\title{
Environmental Adaptation of Construction Barriers under Intuitionistic Fuzzy Theory
}

\author{
Katarina Rogulj, Jelena Kilić Pamuković
}

\begin{abstract}
The project of construction barriers removal is a comprehensive planning task and it demands a suitable support for identification, and priority ranking of facilities necessary for barriers removal. This paper proposes a multicirteria Intuitionistic Fuzzy (IF) ELECTRE model to support decision makers in the process of managing of removal project of construction barriers for physically disabled in high schools. IF ELECTRE approach is used to deal with complex problems, where decision-makers have ambiguities and dualities in evaluation of considered solution. Hereby 17 high schools are defined and seven criteria are determined by decision-makers. These criteria are further used for the alternatives assessments. Each DM is also evaluated by linguistic and numerical values, assigning them this way an importance according to their background and the years of experience. The Intuitionistic Fuzzy Weighted Average (IFWA) operator is calculated to achieve aggregated alternatives evaluations. Furthermore, concordance and discordance sets and indexes are calculated to obtain dominance matrix and final ranking of schools for the construction barriers removal. The model is validated on high schools in the city of Split. Using IF theory, the given problematic can be operated more effectively by diminishing the inaccuracy of available information.
\end{abstract}

Keywords: construction barriers; ELECTRE; Intuitionistic Fuzzy Theory; multicriteria decision-making; physically disabled

\section{INTRODUCTION}

Identifying constriction barriers in the physical world demands taking into account the positioning of necessary ramps, elevators, lifts, adjustment of sanitary elements, etc. To eliminate the construction barriers as much as possible, designers, spatial planners, architects, transportation planners, construction contractors, and many others must have a crucial role in such projects. Before construction even begins, the process requires an effective cooperation between spatial planners, architects, contractors and end-user. Such a cooperation results in constructing the facilities that serve to the public, and are economically practicable, and enables creative design [1]. Managing this type of projects is a complex and poorly structured task, because it includes various aspects which seek a holistic approach. To deal with this problems, systematic and sustainable decision procedures are needed in management activities. Also, there is a significant lack of approaches that deal with this type of problem under the multicriterial decision making (MCDM) environment. According to Kassab et al. [2], MCDM is a decision analysis tool that is beneficial for the assessment and comparison of the alternatives by multiple criteria, and then ranking of these alternatives from most to least preferred. However, multiple-party problems containing various conflicting criteria, various different solutions and multiple decision makers with different opinions and attitudes are more comprehensive and involve a series of actions by participants, and eventually end in failing with decision or indecision.

Therefore, in this paper, a MCDM model is proposed. More particularly presented research refers to construction barriers in public education facilities such are high schools (HS) in urban and suburban areas. The approach is designed to be used at a local governmental level. The aim of the research is to resolve the multicriterial problem dealing with the removal of construction barriers in school facilities by provision of a unique multicirterial model, which stands as a tool for planners dealing with this issue. MCDM is used for solving various complex problems with multiple criteria, solutions and decision-makers to give a support in finding the most appropriate alternative. Although, the problem of construction barriers removal is muclticirterial, it is not sufficient to use classical MCDM method due to the uncertain information and duality in decision maker's evaluations.

Nowadays, classical MCDM methods are not efficient when dealing with uncertain and vagueness data in decisionmaking process. Zadeh [3] proposed Fuzzy Set Theory, which was lately integrated in MCDM methods. This tool is very effective when it comes to uncertain data. Since classical Fuzzy Set Theory is shown to be hard for decision makers to quantify opinions between zero and one, an Intuitionistic Fuzzy Theory (IFT), developed by Atanassov $[4,5]$, has shown to be more applicable. The Intuitionistic Fuzzy Sets (IFS) are characterized by three degrees: membership, non-membership, and hesitancy. In recent years, the IFS has been applied in many fields such as decision-making problems, pattern recognition, health and medical diagnostic, supplier selection, personnel selection, selection of the facility location, and evaluation of renewable energy.

Atanassov, Pasi, and Yager [6] proposed an intuitionistic fuzzy interpretation of multi-stakeholders and MCDM. Each decision maker evaluated the alternatives according to each defined criterion: their evaluations are described as numeric values under the intuitionistic IFT. Hong and Choi [7] developed new functions to measure the degree of accuracy of membership of each alternative evaluate by criteria which are presented as uncertain values. Hung and Yang [8] in their study gave an approach for measuring distance between IFSs which is based on the Hausdorff distance. A new method for solving MCDM problem under IFT is presented by Liu and Wang [9] They firstly defined an evaluation function which served to measure the degrees of satisfaction and nonsatisfaction of alternatives. After that, the concept of intuitionistic fuzzy operators is described. Szmidt and Kacprzyk [10], in their study have has determined solutions in group decision using IFS, while in [11] they extended the idea of a fuzzy logic to a state when individual opinions are introduced as IF preference relations. Wang [12] proposed a decision approach under ambiguity information to service 
selection application based on Quality of Services. Xu [13] gave a detailed description of preference relations and their properties. In addition, they proposed new preference relations. $\mathrm{Xu}$ [14] proposes definition of terms of positive and negative ideal intuitionistic fuzzy set. They applied the measure of similarity to MCDM combined with IFT, while [15] proposed accuracy function for IFS. Another similarity measure between IFS was developed by Xu and Yager [16] which was further applied in group decision making consensus analysis.

$\mathrm{Li}$ and Cheng [17] presented a new concept of similarity between IFSs and its application to problems of pattern recognition. Liang and Shi [18] also introduced some new similarity measures of IFSs, and applied them to pattern recognition example to gain more reasonable results than those from existing methods. An information-theoretic approach for IFSs is introduced by Vlachos \& Sergiadis [19], and applied to the problems of pattern recognition. Similar study was presented by Wang and Xin [20] who developed some new distance measures of IFSs to pattern recognition applications, and Zhang and $\mathrm{Fu}$ [21] proposed a new methodology for measuring the similarity degree between three fuzzy sets and between IFSs.

An IF MCDM methodology is proposed by Boran [22], integrating TOPSIS (Technique for Order Preference by Similarity to Ideal Solution) method into the IFT to selection of facility location, while Boran, Genc and Akay [24] proposed an IF group MCDM with TOPSIS method to the supplier selection problem. Comparison of the renewable energy technologies for generating electricity is presented by Boran, Boran, and Menlik [25] using TOPSIS based on IFT, and also, Roy [26] presented methodology under IFT for evaluation of renewable energy.

The ELECTRE method was developed by Roy [27]. It supports the decision making problems with qualitative or quantitative criteria. The ELECTRE stands for ELimination Et Choix Traduisant la REalite [28] and was at first cited ELECTRE for trading reasons [32]. This approach has evolved into different variants, known as ELECTRE I, ELECTRE II [29], and ELECTRE III [30, 31]. The idea of ELECTRE concerning concordance, discordance and outranking concepts originate from real-world applications, and it uses concordance and discordance to analyze outranking relations among solutions [32]. The method is based on a pair-wise solutions' comparison. These comparisons are compounded of evaluated information obtained from decision maker. The decision maker uses concordance and discordance sets and indices to analyze relations among different alternatives and to choose the best one. The ELECTRE method includes evaluation information, which are fuzzy and mostly not applicable to the real-life decision-making problems [23]. Hereby ELECTREE method is proposed with IF Theory to gain more accurate and precise results. Furthermore, IFT can be used to evaluate different solutions and to classify different kinds of concordance and discordance sets to fit the real decisionmaking process. In this paper, the model of IF ELECTRE is proposed to managing the project of removal of construction barriers in high schools' facilities. The model is validated on the high schools in the city of Split, Croatia.

\subsection{Literature Review}

In the previous studies authors performed qualitative and quantitative research on construction barriers. They gave a list of construction barriers of facilities; access measures for them; and ways to improve through renovation, remodeling, and removing barriers across the urban landscape. Woolley [34] in their study identified the barriers to the outdoor play spaces for children with disabilities. Agarwal et al. [35] studied disabled students who faced various structural barriers, such as lack of ramps or elevators in school facilities, heavy doors, inaccessible washrooms, and inaccessible transportation to and from school, lack of automatic doors, etc. The photo voice method was used to gather images with construction barriers. Hammel et al. [36] developed a framework to describe how environmental factors influence the participation of people with disabilities, highlighting domains of facilitators and barriers.

Church and Marston [37] measured an access for people with physical impairments within urban areas that extends beyond the standard-based approach. Martin [38] gave a qualitative and quantitative overview on physical activity engagement of the disabled from a social relational model perspective. Hannon [39] analyzed the general physical accessibility of facilities in the Munster region, while Kroll et al. [40] made an exploratory study to investigate how the physically disabled struggle with access barriers, and to define strategies to increase access to needed services. Kayes et al. [41] adopted a qualitative research on physical barriers as an interference for physical activity for people with multiple sclerosis. Yuker et al. [42] gave a comprehensive source of information pertinent to the education of physically disabled, with an accent on the construction of facility barriers. Leigh Hill [43] examined the level of physical accessibility for students with disabling conditions in universities across Canada, while Klinger [44] examined the evidence of the physical accessibility of schools for students with mobility impairments and provided an overview of the barriers and facilitators. Burton et al. [45] presented findings from a project that examined the environmental, and institutional barriers faced by disabled people. Martin Ginis et al. [46] made a review of published studies of factors related to leisure-time physical activity among people with physical disabilities.

None of the mentioned studies dealt with the construction barriers removal as a multicriterial problem and none has developed any type of model to solve vagueness and duality in the observed problems.

\section{METHODOLOGY}

Atanassov [4] developed the IFS theory to deal with uncertainty. In this section, a review of some necessary concepts related to intuitionistic fuzzy sets is given.

Definition 1: Let $X$ be a finite set, and let $A \subset X$ be a fixed set [5]. Where $X$ can be described as:

$X=\left\{a, \mu_{x}(a), v_{x}(a) \mid a \in A\right\}$ 
Where

$$
\begin{aligned}
& \mu_{x}(a): \mu_{x}(a) \in[0,1], S \rightarrow[0,1] \\
& v_{x}(a): v_{x}(a) \in[0,1], S \rightarrow[0,1]
\end{aligned}
$$

Membership and non-membership functions can be explained as:

$$
0 \leq \mu_{x}(a)+v_{x}(a) \leq 1 \quad \forall s \in S, R \rightarrow[0,1]
$$

Definition 2: The hesitation degree of IFS is $\pi_{x}(a)$ and can be described as:

$$
\pi_{x}(a)=1-\mu_{x}(a)-v_{x}(a)
$$

where $\pi_{x}(a)$ is degree of uncertainity of $x$ to $A$.

Let $Z$ and $Y$ be IFSs of the set $A$, then multiplication operators are [4]:

$$
\begin{aligned}
& Z+Y= \\
& =\left\{\mu_{z}(a) \cdot \mu_{y}(a), v_{z}(a)+v_{y}(a)-v_{z}(a) \cdot v_{y}(a) \mid s \in S\right\}
\end{aligned}
$$

In this section, an IF ELECTRE approach is presented to the project management of construction barriers removal in HS objects. In proposed algorithm, the judgments provided by different decision makers are given as well as the quantitative and the qualitative data $[32,33]$. Three groups of experts are asked to compare each alternative by each criterion. The algorithm is described in an eight-step, and presented in Fig. 1.

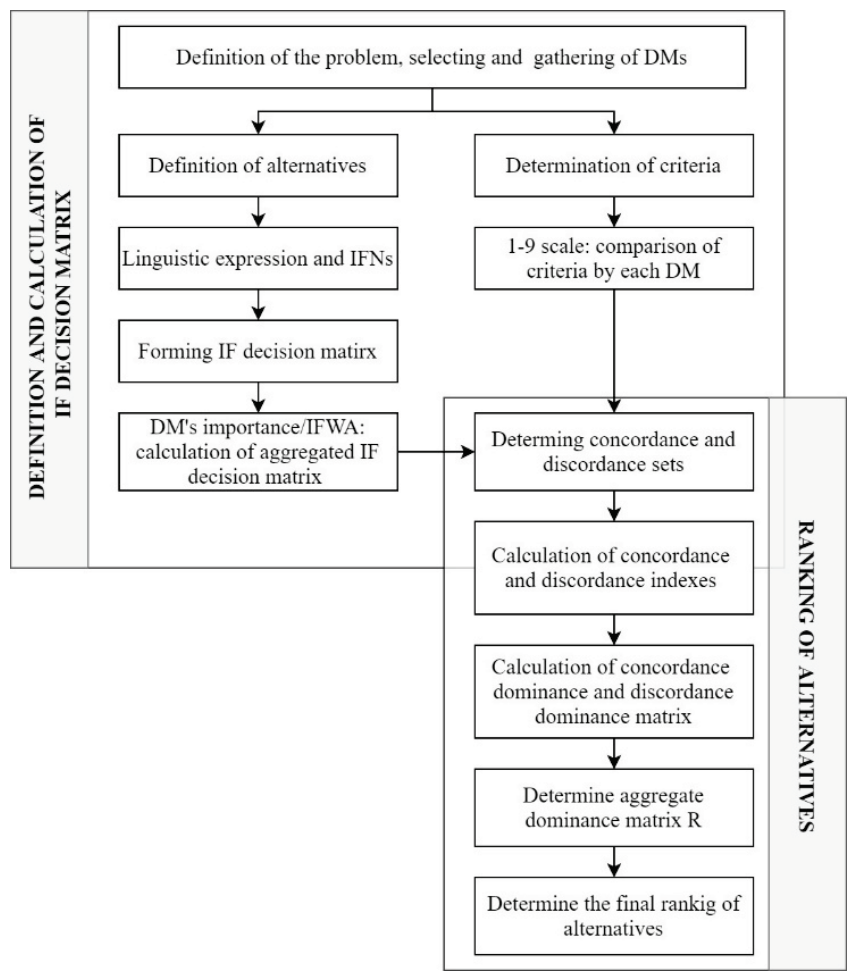

Figure 1 IF ELECTRE model to project management of construction barriers
Algorithm:

Step1. Criteria weight determination by pariwise comparions using 1-9 scale developed by Saaty [47].

Step2. DMs importance calculation using Boran et al. [48] expression:

$\lambda_{l}=\frac{\left(\mu_{l}+\pi_{i}\left(\frac{\mu_{l}}{\mu_{l}+v_{l}}\right)\right)}{\sum_{l=1}^{k}\left(\mu_{l}+\pi_{i}\left(\frac{\mu_{l}}{\mu_{l}+v_{l}}\right)\right)}$

where $\lambda_{l} \in[0,1]$ and $\sum_{l=1}^{k} \lambda_{l}=1$.

Step3. Calculation of aggregated intuitionistic fuzzy decision matrix using DMs' importance as the base to equation of IFWA operator [49]. Each DM's opinion is merged into single opinion.

Let $P^{(l)}=\left(p_{i j}^{(l)}\right)_{m * n}$ be the IF decision matrix of each DM. $\lambda=\left\{\lambda_{1}, \lambda_{2}, \ldots, \lambda_{k}\right\}$ is the importance of the DM.

$P=\left(p_{i j}\right)_{m^{\prime} * n^{\prime}}$

Where

$$
\begin{aligned}
& p_{i j}=I F W A p_{\lambda}\left(p_{i j}^{(1)}, p_{i j}^{(2)}, \ldots, p_{i j}^{(k)}\right)=\lambda_{1} p_{i j}^{(1)}+\lambda_{2} p_{i j}^{(2)}+\ldots+\lambda_{k} p_{i j}^{(k)}= \\
& =\left[1-\prod_{i=1}^{k}\left(1-\mu_{i j}^{(l)}\right)^{\lambda_{l}}, \prod_{i=1}^{k}\left(v_{i j}^{(l)}\right)^{\lambda_{l}}, \prod_{i=1}^{k}\left(1-\mu_{i j}^{(l)}\right)^{\lambda_{l}}-\prod_{i=1}^{k}\left(v_{i j}^{(l)}\right)^{\lambda_{l}}\right]
\end{aligned}
$$

Hereby, decision problem is described as:

$$
P_{i j}=\left[\begin{array}{cccc}
p_{11} & p_{12} & \cdots & p_{1 n} \\
p_{21} & p_{22} & \cdots & p_{2 n} \\
\vdots & \vdots & \ddots & \vdots \\
p_{m 1} & p_{m 2} & \cdots & p_{m n}
\end{array}\right]
$$

$P_{i j}=\left(\mu_{i j}, v_{i j}, \pi_{i j}\right)(i=1,2, \ldots, m ; j=1,2, \ldots, n)$ is an element of aggregated intuitionistic fuzzy decision matrix.

Step4. Calculation of the concordance and discordance sets where $C_{z y}$ shows the degree of confidence in the pairwise comparison of the $z$ and $y$ alternatives $\left(X_{z} \rightarrow X_{y}, x, y=1,2\right.$, $\ldots, m ; z \neq y)$. The concordance set $C_{z y}^{(1)}$ of $Z_{k}$ and $Y_{l}$ is composed of all criteria for which $Z_{k}$ is preferred to $Y_{l}$. The concordance set is defined as:

$C_{z y}^{(1)}=\left\{l \mid \mu_{z l} \geq \mu_{l y}, v_{z l}<v_{l y}, \pi_{z l}<\pi_{l y}\right\}$

The midrange concordance set is defined as:

$C_{z y}^{(2)}=\left\{l \mid \mu_{z l} \geq \mu_{l y}, v_{z l}<v_{l y}, \pi_{z l} \geq \pi_{l y}\right\}$

The weak concordance set is defined as 
$C_{z y}^{(3)}=\left\{l \mid \mu_{z l} \geq \mu_{l y}, v_{z l} \geq v_{l y}\right\}$

The discordance set is composed of all criteria for which $Z_{k}$ is not preferred to $Y_{l}$. The degree of disagreement in $\left(X_{z} \rightarrow\right.$ $X_{y}$ ) is constructed as follows:

$D_{z y}^{(1)}=\left\{l \mid \mu_{z l}<\mu_{l y}, v_{z l} \geq v_{l y}, \pi_{z l} \geq \pi_{l y}\right\}$

The midrange discordance set is defined as follows:

$D_{z y}^{(2)}=\left\{l \mid \mu_{z l}<\mu_{l y}, v_{z l} \geq v_{l y}, \pi_{z l}<\pi_{l y}\right\}$

The weak discordance set is defined as follows:

$D_{z y}^{(3)}=\left\{l \mid \mu_{z l}<\mu_{l y}, v_{z l}<v_{l y}\right\}$

Step5. Determination of the concordance index $C_{z y}$ and the discordance index $D_{z y}$ for the proposed model using IFS is defined as follows:

$C_{z y}=w_{c}^{(1)} * \sum_{i \in c_{z y}^{1}} w_{l}+w_{c}^{(2)} * \sum_{i \in c_{z y}^{2}} w_{l}+w_{c}^{(3)} * \sum_{i \in c_{z y}^{3}} w_{l}$

The concordance index is equal to the sum of the weights of criteria that are contained in the concordance sets, where $w_{c}^{(1)}, w_{c}^{(2)}$, and $w_{c}^{(3)}$ are the weights of the concordance, midrange concordance, and weak concordance sets, respectively. The assessments of a $Z_{k}$ are worse than assessments of a competing $Y_{l}$. Hereby, the discordance index is defined as follows:

$$
D_{z y}=\frac{\max _{j \in D_{i j}} W_{D} \times d\left(x_{i l}, x_{l j}\right)}{\max _{j \in D_{i j}} d\left(x_{i l}, x_{l j}\right)}
$$

Where $W_{D}$ is equal to $w_{D}^{(1)}, w_{D}^{(2)}$ or $w_{D}^{(3)}$. These sets integrate the weight of discordance, midrange discordance, and weak discordance sets, respectively. The distance between $X_{i l}$ and $X_{l j}$ is shown as:

$$
d\left(x_{i l}, x_{l j}\right)=\sqrt{\frac{1}{2 n} \sum_{j=1}^{n}\left(\left(\mu_{i l}-\mu_{l j}\right)^{2}+\left(v_{i l}-v_{l j}\right)^{2}+\left(\pi_{i l}-\pi_{l j}\right)^{2}\right)}
$$

Where $d\left(x_{i l}, x_{l j}\right)$ is Euclidian distance between $X_{i l}$ and $X_{l j}$.

Step6. In the concordance dominance matrix calculation process, the chosen alternative has the shortest distance from the positive ideal solution. Hence, the concordance dominance matrix $\boldsymbol{K}$ can be defined as:

$$
K_{i j}=\left(C_{z y}\right)^{*}-\left(C_{z y}\right)_{i j}
$$

where $\left(C_{z y}\right)^{*}$ is the maximum value of $\left(C_{z y}\right)_{i j}$, and $C_{z y} \geq C$, where $C=\frac{\sum_{z=1, z \neq y}^{m} \sum_{y=1, y \neq z}^{m} C_{z y}}{m(m-1)}$, which refers to the separation of each alternative from the positive ideal solution. A higher value of $K_{i j}$ indicates that $Z_{k}$ is less favorable than $Y_{l}$.

In the discordance dominance matrix calculation, the chosen alternative has the longest distance from the negative ideal solution. Hence, the discordance dominance matrix $\boldsymbol{L}$ is defined as follows:

$$
L_{i j}=\left(D_{z y}\right)^{*}-\left(D_{z y}\right)_{i j}
$$

where $\left(D_{z y}\right)^{*}$ is the minimum value of $\left(D_{z y}\right)_{i j}$, and $D_{z y} \geq D$, where $D=\frac{\sum_{z=1, z \neq y}^{m} \sum_{y=1, y \neq z}^{m} D_{z y}}{m(m-1)}$, which refers to the separation of each alternative from the negative ideal solution. A higher value of $L_{i j}$ indicates that $Z_{k}$ is preferred to $Y_{l}$.

Step7. To determine aggregate dominance matrix, the distance of each alternative to both positive and negative ideal alternatives should be calculated to determine the ranking. Hence, the aggregate dominance matrix $\boldsymbol{R}$ is defined as follows:

$$
R_{i j}=\left[\begin{array}{ccccc}
- & r_{12} & \cdots & \cdots & r_{1 m} \\
r_{21} & - & r_{23} & \cdots & r_{2 m} \\
\cdots & \cdots & - & \cdots & \cdots \\
r_{(m-1) m} & \cdots & \cdots & - & r_{(m-1) m} \\
r_{m 1} & r_{m 2} & \cdots & r_{m(m-1)} & -
\end{array}\right]
$$

Where $r_{k l}=\frac{l_{k l}}{k_{k l}+l_{k l}}$, and $l_{k l}$ and $k_{k l}$ are defined in (18) and (19), respectively. $r_{k l}$ refers to the relative closeness to the ideal alternative, with a range from 0 to 1 . Higher the value of $r_{k l}$, closer is the alternative $X_{k}$ to the positive ideal and more distant form the negative ideal solution then the alternative $X_{l}$. Hence, it is better solution.

Step8. In final ranking of the alternatives, determination of matrix $\boldsymbol{T}$ is needed. $T_{i j}$ is the final value of assessment, and is defined as follows:

$T_{k l}=\frac{1}{m-1} \sum_{l=1, l \neq k}^{m} r_{k l} \quad k=1,2, \ldots, m$

Alternatives are ranked according to $T_{i j}$. The best alternative $X^{*}$, which is the one with the shortest distance to the positive ideal point and the longest distance from the negative ideal point, and is defined as:

$$
X^{*}=\max \left(T_{i j}\right)
$$


Where $X^{*}$ is the best atlernative.

\section{RESULTS AND DISCUSSION}

In this section, the proposed model is applied on the HS facilities. There are 17 HSs in the City of Split that need construction barriers removal for the physically disabled. These construction barriers are mostly related to the external access of school buildings and other facilities. Furthermore, the existence of a ramp and elevator outside and inside schools and school facilities is missing. Also, an appropriate front door width, and the existence of access to sanitary facilities that are adapted to people with disabilities are crucial to embed. The Department of Construction and Urban Planning is continuously taking measures to adapt facilities for disabled students, urgently fulfilling the needs of schools [50]. In Tab. 1, a list of HSs necessary for construction barriers removal are presented.

Table 1 List of HSs for construction barriers removal project

\begin{tabular}{|c|c|}
\hline HS & High School name \\
\hline HS1 & II. Grammar School \\
\hline HS2 & IV. Grammar School \\
\hline HS3 & V. Grammar School \\
\hline HS4 & Science-technical sch. \\
\hline HS5 & Construction-geodetic sch. \\
\hline HS6 & Electrotechnic sch. \\
\hline HS7 & Industrial sch. \\
\hline HS8 & Trade sch. \\
\hline HS9 & Technic sch. \\
\hline HS10 & Touristic-hospitality sch. \\
\hline HS11 & Art sch. \\
\hline HS12 & Trade-technic sch. \\
\hline HS13 & Commercial-trade sch. \\
\hline HS14 & Maritime sch. \\
\hline HS15 & Music sch. Josip Hatze \\
\hline HS16 & Technical-traffic sch. \\
\hline HS17 &
\end{tabular}

Furthermore, to support final decision-makers in managing the projects of removal of constrain barriers in HSs, which is a problematic with a high uncertainty and duality, all HSs must be evaluate by certain number of criteria. Decision-makers, three in this case, define these criteria. A list of criteria is given in Tab. 2, and only the crucial one are presented to avoid extensive calculations and data presentation.

Table 2 Final list of criteria

\begin{tabular}{|c|c|}
\hline Criterion & Criterion name \\
\hline C1 & Number of construction barriers \\
\hline C2 & External access to school's facilities \\
\hline C3 & Ramp or elevator inside school's facilities \\
\hline C4 & Adjusted door width \\
\hline C5 & Adjusted sanitary access in the building \\
\hline C6 & Cost of project documentation \\
\hline C7 & Amount of investment \\
\hline
\end{tabular}

After the relevant cirteria are defined, the comparison of all criteria is done using 1-9 number scale defined by Saaty
[47]. Each decision-maker (DM) made a comparison. The 19 scale is given in Tab. 3, while calculated criteria weights by each DM and aggregated weight are presented in Tab. 4 .

Table 3 The basic 1-9 scale [47]

\begin{tabular}{|c|c|}
\hline Importance & Definition \\
\hline 1 & Same significance \\
\hline 3 & Average significance of one over another \\
\hline 5 & Powerful significance of one over another \\
\hline 7 & Very powerful significance of one over another \\
\hline 9 & Extreme significance of one over another \\
\hline $2,4,6,8$ & Intermediate values \\
\hline
\end{tabular}

Table 4 Calculated criteria weights

\begin{tabular}{|c|c|c|c|c|}
\hline & DM1 & DM2 & DM3 & $W$ \\
\hline 1 & 0.20 & 0.25 & 0.20 & 0.22 \\
\hline C2 & 0.05 & 0.06 & 0.03 & 0.05 \\
\hline C3 & 0.15 & 0.06 & 0.03 & 0.08 \\
\hline C5 & 0.05 & 0.06 & 0.03 & 0.05 \\
\hline C6 & 0.05 & 0.06 & 0.03 & 0.05 \\
\hline C7 & 0.25 & 0.35 & 0.13 & 0.24 \\
\hline
\end{tabular}

The linguistic expressions of DM's importance with IF numbers are given in Tab. 5. Each DM is evaluated according to his/her background and years of experience. Using Eq. (6) the importance for each DM is calculated, and presented in Tab. 6 with linguistic and numerical value.

Table $\mathbf{5}$ Linguistic expressions and IFNs for DM's importance

\begin{tabular}{|c|c|}
\hline Linguistic expression & IFNs \\
\hline Very Important (VI) & $(0.8,0.1,0.1)$ \\
\hline Important (I) & $(0.6,0.3,0.1)$ \\
\hline Medium (M) & $(0.5,0.5,0.0)$ \\
\hline Bad (B) & $(0.3,0.6,0.1)$ \\
\hline Very Bad (VB) & $(0.1,0.8,0.1)$ \\
\hline
\end{tabular}

Table 6 Calculated importance of DMs

\begin{tabular}{|c|c|c|c|}
\hline & DM1 & DM2 & DM3 \\
\hline $\begin{array}{c}\text { Linguistic } \\
\text { expression }\end{array}$ & VI & I & M \\
\hline$\lambda$ & 0.41 & 0.34 & 0.25 \\
\hline
\end{tabular}

Furthermore, the linguistic expressions for the alternatives assessments are given in Tab. 7 with appurtenant IF numbers, and are further used to evaluate each HS by each criterion. The alternatives assessments are calculated by IFWA operator, defined in Eq. (7). The membership, nonmembership and hesitation degree are determined as common values of all DMs' opinions that were included in the evaluation process. The aggregated IF decision matrix is presented in Tab. 8.

Table 7 Linguistic expression and IFNs for alternatives assessment

\begin{tabular}{|c|c|}
\hline Linguistic expression & IFNs \\
\hline Very Good (VG) & $(0.9,0.05,0.05)$ \\
\hline Good (G) & $(0.7,0.2,0.1)$ \\
\hline Medium (M) & $(0.5,0.5,0.0)$ \\
\hline Bad (B) & $(0.2,0.7,0.1)$ \\
\hline Very Bad (VB) & $(0.05,0.9,0.05)$ \\
\hline
\end{tabular}


Table 8 IFWA: aggregated IF decision matrix

\begin{tabular}{|c|c|c|c|c|c|c|c|}
\hline Alt. & $\mathrm{C} 1$ & $\mathrm{C} 2$ & $\mathrm{C} 3$ & $\mathrm{C} 4$ & $\mathrm{C} 5$ & C6 & $\mathrm{C} 7$ \\
\hline HS1 & $(0.20,0.70,0.10)$ & $(0.70,0.20,0.10)$ & $(0.20,0.70,0.10)$ & $(0.20,0.70,0.10)$ & $(0.70,0.20,0.10)$ & $(0.70,0.20,0.10)$ & $(0.70,0.20,0.10)$ \\
\hline HS2 & $(0.50,0.50,0.00)$ & $(0.70,0.20,0.10)$ & $(0.70,0.20,0.10)$ & $(0.70,0.20,0.10)$ & $(0.20,0.70,0.10)$ & $(0.50,0.50,0.00)$ & $(0.50,0.50,0.00)$ \\
\hline HS3 & $(0.50,0.50,0.00)$ & $(0.70,0.20,0.10)$ & $(0.70,0.20,0.10)$ & $(0.70,0.20,0.10)$ & $(0.20,0.70,0.10)$ & $(0.56,0.40,0.04)$ & $(0.56,0.40,0.04)$ \\
\hline HS4 & $(0.05,0.90,0.05)$ & $(0.20,0.70,0.10)$ & $(0.20,0.70,0.10)$ & $(0.20,0.70,0.10)$ & $(0.20,0.70,0.10)$ & $(0.90,0.05,0.05)$ & $(0.90,0.05,0.05)$ \\
\hline HS5 & $(0.50,0.50,0.00)$ & $(0.70,0.20,0.10)$ & $(0.20,0.70,0.10)$ & $(0.70,0.20,0.10)$ & $(0.70,0.20,0.10)$ & $(0.56,0.40,0.04)$ & $(0.56,0.40,0.04)$ \\
\hline HS6 & $(0.20,0.70,0.10)$ & $(0.70,0.20,0.10)$ & $(0.20,0.70,0.10)$ & $(0.70,0.20,0.10)$ & $(0.05,0.90,0.05)$ & $(0.70,0.20,0.10)$ & $(0.70,0.20,0.10)$ \\
\hline HS7 & $(0.05,0.90,0.05)$ & $(0.20,0.70,0.10)$ & $(0.20,0.70,0.10)$ & $(0.20,0.70,0.10)$ & $(0.05,0.90,0.05)$ & $(0.90,0.05,0.05)$ & $(0.90,0.05,0.05)$ \\
\hline HS8 & $(0.05,0.90,0.05)$ & $(0.20,0.70,0.10)$ & $(0.20,0.70,0.10)$ & $(0.70,0.20,0.10)$ & $(0.20,0.70,0.10)$ & $(0.90,0.05,0.05)$ & $(0.90,0.05,0.05)$ \\
\hline HS9 & $(0.50,0.50,0.00)$ & $(0.70,0.20,0.10)$ & $(0.50,0.50,0.00)$ & $(0.50,0.50,0.00)$ & $(0.20,0.70,0.10)$ & $(0.56,0.40,0.04)$ & $(0.50,0.50,0.00)$ \\
\hline HS10 & $(0.05,0.90,0.05)$ & $(0.20,0.70,0.10)$ & $(0.20,0.70,0.10)$ & $(0.20,0.70,0.10)$ & $(0.05,0.90,0.05)$ & $(0.90,0.05,0.05)$ & $(0.90,0.05,0.05)$ \\
\hline HS11 & $(0.05,0.90,0.05)$ & $(0.70,0.20,0.10)$ & $(0.20,0.70,0.10)$ & $(0.20,0.70,0.10)$ & $(0.20,0.70,0.10)$ & $(0.90,0.05,0.05)$ & $(0.90,0.05,0.05)$ \\
\hline HS12 & $(0.50,0.50,0.00)$ & $(0.70,0.20,0.10)$ & $(0.20,0.70,0.10)$ & $(0.50,0.50,0.00)$ & $(0.70,0.20,0.10)$ & $(0.56,0.40,0.04)$ & $(0.56,0.40,0.04)$ \\
\hline HS13 & $(0.05,0.90,0.05)$ & $(0.20,0.70,0.10)$ & $(0.05,0.90,0.05)$ & $(0.70,0.20,0.10)$ & $(0.20,0.70,0.10)$ & $(0.90,0.05,0.05)$ & $(0.90,0.05,0.05)$ \\
\hline HS14 & $(0.05,0.90,0.05)$ & $(0.20,0.70,0.10)$ & $(0.05,0.90,0.05)$ & $(0.50,0.50,0.00)$ & $(0.70,0.20,0.10)$ & $(0.90,0.05,0.05)$ & $(0.90,0.05,0.05)$ \\
\hline HS15 & $(0.20,0.70,0.10)$ & $(0.20,0.70,0.10)$ & $(0.05,0.90,0.05)$ & $(0.70,0.20,0.10)$ & $(0.70,0.20,0.10)$ & $(0.70,0.20,0.10)$ & $(0.70,0.20,0.10)$ \\
\hline HS16 & $(0.05,0.90,0.05)$ & $(0.20,0.70,0.10)$ & $(0.05,0.90,0.05)$ & $(0.50,0.50,0.00)$ & $(0.05,0.90,0.05)$ & $(0.90,0.05,0.05)$ & $(0.90,0.05,0.05)$ \\
\hline HS17 & $(0.05,0.90,0.05)$ & $(0.20,0.70,0.10)$ & $(0.20,0.70,0.10)$ & $(0.70,0.20,0.10)$ & $(0.20,0.70,0.10)$ & $(0.90,0.05,0.05)$ & $(0.90,0.05,0.05)$ \\
\hline
\end{tabular}

Applying step 4, and using aggregated IF values of HS evaluations, the concordance sets are defined. The concordance set, applying (9), is defined as follows:

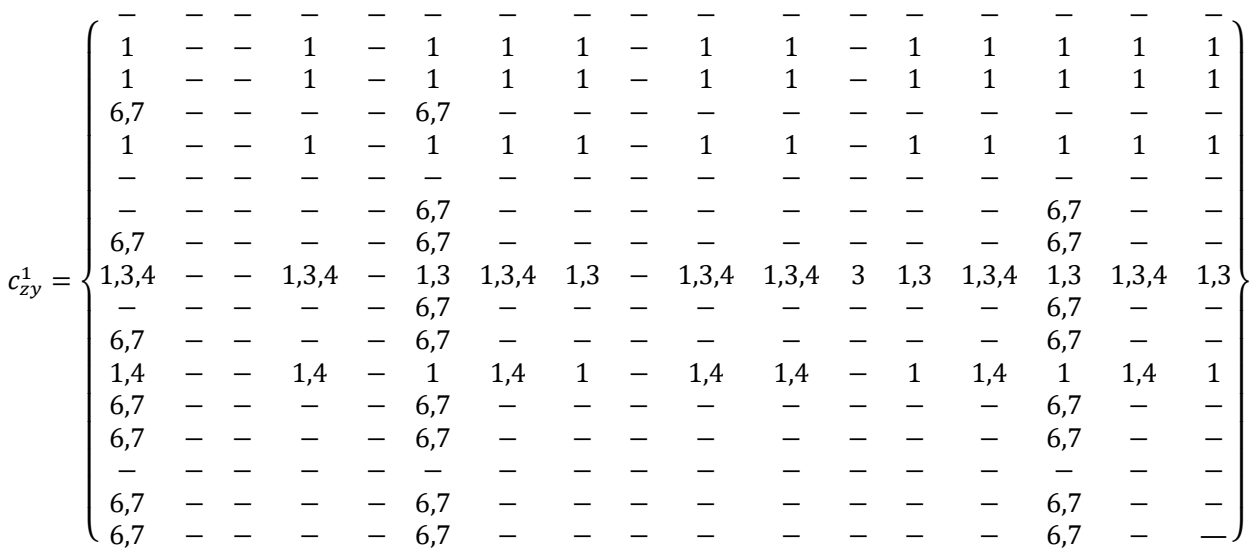

Then, the midrange concordance set, applying (10), is:

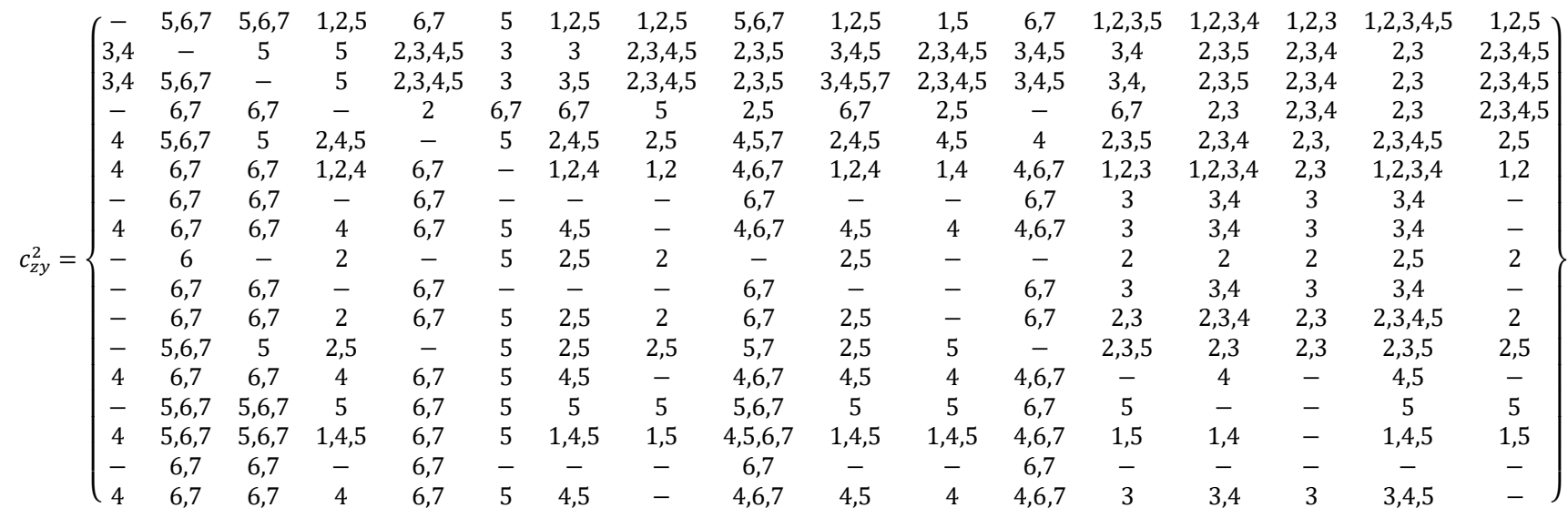


And the weak concordance set, applying (11), is defined as:

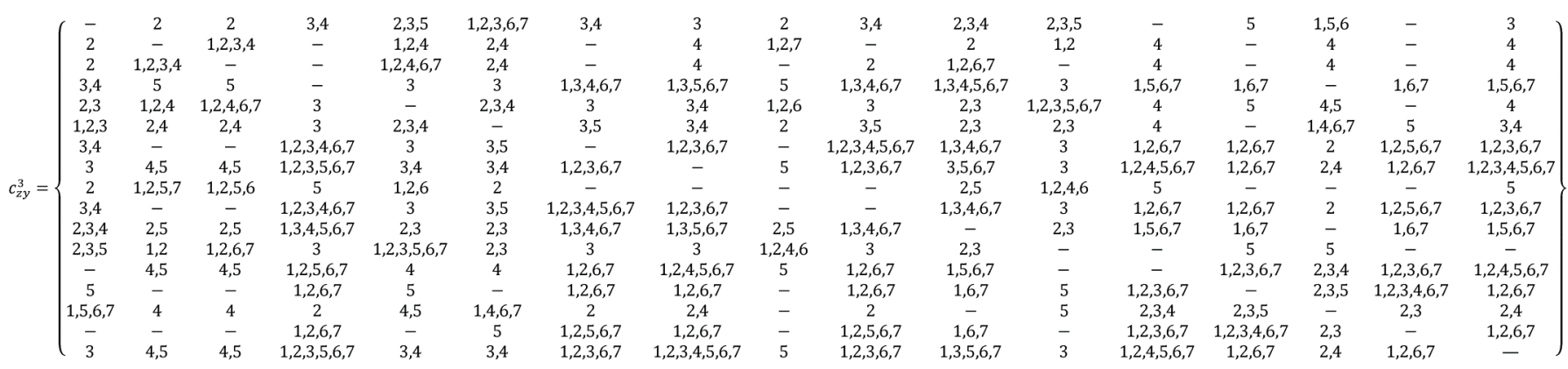

The discordance set is determined using (12), and given as follows:

$$
D_{z y}^{1}=\left\{\begin{array}{ccccccccccccccccc}
- & 1,3,4 & 1,3,4 & - & 4 & 4 & 6,7 & 4,6,7 & 1,3,4 & 6,7 & 6,7 & 1,4 & 4,6,7 & 6,7 & 4 & 6,7 & 4,6,7 \\
5 & - & - & - & 5 & 4 & - & - & - & - & - & 5 & - & 5 & 5 & - & - \\
5 & - & - & - & 5 & - & - & - & - & - & - & 5 & - & 5 & 5 & - & - \\
2,5 & 1,2,3,4 & 1,2,3,4 & - & 1,2,4,5 & 1,2,4 & - & 4 & 1,2,3,4 & - & 2 & 1,2,4,5 & 4 & 5 & 5 & - & 4 \\
- & 3 & 3 & - & - & - & - & - & 3 & - & - & - & - & - & - & - & - \\
- & 1,3 & 1,3 & 6,7 & 1 & - & 6,7 & 6,7 & 6,7 & 6,7 & 6,7 & - & 6,7 & 6,7 & - & 6,7 & 6,7 \\
2 & 1,2,3,4 & 2,3,4 & 2,3 & 1,2,4 & 2,4 & - & 4 & 2,3,4 & - & 2 & 4 & - & 4,5 & 4 & 4 & 4 \\
2 & 1,2,3 & 1,2,3 & - & 1,2,3 & 2 & - & - & 1,2,3 & 4 & 2 & 2,5 & - & 5 & 4,5 & - & - \\
5 & - & - & - & 5 & - & - & - & - & - & - & - & - & 5 & - & - & 5 \\
2 & 2,3 & 3,4 & - & 2,4 & 2,4 & - & 4 & 1,2,3,4 & - & 2 & 1,2,4 & 4 & - & 4 & 4,5 & 4 \\
- & 1,3,4 & 1,3,4 & - & 1 & 4 & - & - & 1,4 & - & - & 1,4,5 & 4,5 & 2,3 & 2,4,5 & 2,4 & 2,5 \\
- & 3 & 3 & - & - & - & - & - & 3 & - & - & - & - & - & - & - & - \\
2 & - & 2 & - & 2 & 2 & - & - & 1,2 & - & 2 & 2,5 & - & 5 & 5 & - & - \\
2 & 1 & - & - & 1,2 & 2 & - & - & 1 & 2,3 & 2 & 1,2 & - & - & - & - & - \\
- & 1,2 & 1,2 & 6,7 & 1,2 & - & 6,7 & - & 1,2,3 & 6,7 & 2,6,7 & 6,7 & 6,7 & 6,7 & - & 6,7 & 6,7 \\
2 & 1,2 & 1,2 & - & 1,2 & 2 & - & - & 2 & - & 2 & 1,2 & - & - & - & - & - \\
2,5 & 1,2,3 & 1,2,3 & - & 1,2,5 & 2 & - & - & 1,2,3 & - & 2 & - & - & 5 & 2,5 & - & -
\end{array}\right\}
$$

The midrange discordance set, applying (13), is:

$$
D_{z y}^{2}=\left\{\begin{array}{ccccccccccccccccc}
- & - & - & - & - & - & - & - & - & - & - & - & - & - & - & - & - \\
7 & - & 7 & 7 & 7 & 7 & 7 & 7 & - & 7 & 7 & 7 & 7 & 7 & 7 & 7 & 7 \\
6,7 & - & - & 6,7 & - & 6,7 & 6,7 & 6,7 & - & 6,7 & 6,7 & - & 6,7 & 6,7 & 6,7 & 6,7 & 6,7 \\
- & - & - & - & - & 1 & - & - & - & - & - & - & - & - & 1 & - & - \\
6,7 & - & - & 6,7 & - & 6,7 & 6,7 & 6,7 & - & 6,7 & 6,7 & - & 6,7 & 6,7 & 6,7 & 6,7 & 6,7 \\
5 & 5 & 5 & 5 & 5 & - & - & 5 & 5 & - & 5 & 5 & 5 & 5 & 5 & - & 5 \\
1 & - & - & - & - & 1 & - & - & - & - & - & - & - & - & 1 & - & - \\
1 & - & - & - & - & 1 & - & - & - & - & - & - & - & - & 1 & - & - \\
6,7 & 3,4 & 3,4,7 & 6,7 & 4,7 & 4,6,7 & 6,7 & 4,6,7 & - & 6,7 & 6,7 & - & 4,6,7 & 6,7 & 4,6,7 & 6,7 & 4,6,7 \\
1 & - & - & - & - & 1 & - & - & - & - & - & - & - & - & 1 & - & - \\
1 & - & - & - & - & 1 & - & - & - & - & - & - & - & - & 1 & - & - \\
6,7 & 4 & 4 & 6,7 & 4 & 4,6,7 & 6,7 & 4,6,7 & - & 6,7 & 6,7 & - & 4,6,7 & 6,7 & 4,6,7 & 6,7 & 4,6,7 \\
1,3 & 3 & 3 & 3 & 3 & 1,3 & 3 & 3 & - & 3 & 3 & 3 & - & - & 1 & - & 3 \\
1,3,4 & 3,4 & 3,4 & 3,4 & 3,4 & 1,3,4 & 3,4 & 3,4 & - & 3,4 & 3,4 & 3 & 4 & - & 1,4 & - & 3,4 \\
3 & 3 & 3 & 3 & 3 & 3 & 3 & 3 & - & 3 & 3 & 3 & - & - & - & - & 3 \\
1,3,4 & 3,4 & 3,4 & 3,4 & 3,4 & 1,3,4 & 3,4 & 3,4 & - & 3,4 & 3,4 & 3 & 4 & - & 1,4 & - & 3,4 \\
1 & - & - & - & - & 1 & - & - & - & - & - & - & - & - & 1 & - & -
\end{array}\right\}
$$

The weak discordance set is defined by (14), and is presented as: $D_{z y}^{3}=\{-\}$.

The concordance and discordance dominance matrices $\boldsymbol{K}$ and $\boldsymbol{L}$ are calculated applying step 6 , then the aggregate dominance matrix $\boldsymbol{R}$ defined by (20) is calculated and presented as follows:

For the final ranking calculation (21) is used, to determine matrix $\boldsymbol{T}$. According to $\boldsymbol{T}$, alternatives are ranked where the best alternative is the one that has the shortest distance from the positive ideal point and the longest distance from the negative ideal point.

The values of $T$ are determined as follows: $T_{1}=0.86 ; T_{2}$
$=0.69 ; T_{3}=0.85 ; T_{4}=0.54 ; T_{5}=0.85 ; T_{6}=0.85 ; T_{7}=0.82 ;$ $T_{8}=0.59 ; T_{9}=0.93 ; T_{10}=0.55 ; T_{11}=0.60 ; T_{12}=0.86 ; T_{13}=$ $0.51 ; T_{14}=0.63 ; T_{15}=0.91 ; T_{16}=0.67 ; T_{17}=0.65$.

Hence, the final ranking of HS according to the necessary for the construction barriers removal is achieved as: HS9 $>$ HS $15>$ HS $12>$ HS $1>$ HS3 $>$ HS $5>$ HS6 $>$ HS $2>$ $\mathrm{HS} 16>\mathrm{HS} 17>\mathrm{HS} 14>\mathrm{HS} 8>\mathrm{HS} 11>\mathrm{HS} 7>\mathrm{HS} 10>\mathrm{HS} 4$ $>$ HS13. Accoridng to final ranking Technic school ihas the highest priory for the caontruction barriers remova, and Trade-technic school the last priory. HS9 has the most constrction barriers, all four of them while HS13 has only one. This way, the porposed model is shown to be applicable and usefull in dealing with this type of civile engineering 
problematics.

$R_{z y}=\left\{\begin{array}{ccccccccccccccccc}- & 1 & 1 & 0.48 & 0.35 & 0.50 & 1 & 1 & 1 & 1 & 1 & 1 & 1 & 1 & 0.36 & 1 & 1 \\ 1 & - & 0.54 & 0.54 & 1 & 1 & 0.54 & 0.41 & 0.48 & 0.54 & 0.41 & 1 & 0.54 & 1 & 1 & 0.54 & 0.41 \\ 1 & 0.29 & - & 1 & 0.34 & 1 & 1 & 1 & 0.48 & 1 & 1 & 0.50 & 1 & 1 & 1 & 1 & 1 \\ 0.28 & 1 & 1 & - & 1 & 0 & 0.22 & 0.50 & 1 & 0.22 & 0.37 & 1 & 0.24 & 0.50 & 0.54 & 0.48 & 0.35 \\ 1 & 0.31 & 0.50 & 1 & - & 1 & 1 & 1 & 0.29 & 1 & 1 & 0.48 & 1 & 1 & 1 & 1 & 1 \\ 0.49 & 0.39 & 0.39 & 1 & 1 & - & 1 & 1 & 1 & 1 & 1 & 0.34 & 1 & 1 & 0.49 & 1 & 1 \\ 0.54 & 1 & 1 & 0.52 & 1 & 1 & - & 0.50 & 0.41 & 0.48 & 0.50 & 0.37 & 0.48 & 0.51 & 0.29 & 0.37 & 0.50 \\ 0.29 & 1 & 1 & 0.48 & 1 & 0.28 & 0.36 & - & 1 & 0.38 & 0.50 & 0.37 & 0.48 & 0.50 & 1 & 0.48 & 0.48 \\ 1 & 0.36 & 1 & 1 & 1 & 1 & 1 & 1 & - & 1 & 1 & 0.48 & 1 & 1 & 1 & 1 & 1 \\ 0.54 & - & - & - & - & 1 & - & - & - & - & - & - & - & - & 1 & - & - \\ 0.28 & 1 & 1 & 0.48 & 0.41 & 0.28 & 0.48 & 0.48 & 1 & 0.36 & - & 1 & 0.51 & 0.39 & 1 & 0.37 & 0.51 \\ 1 & 0.34 & 0.52 & 1 & 0.49 & 1 & 1 & 1 & 0.36 & 1 & 1 & 1 & 1 & 1 & 1 & 1 & 1 \\ 0.32 & 0.36 & 0.38 & 0.50 & 0.38 & 1 & 0.50 & 0.50 & 1 & 0.50 & 0.51 & 0.39 & - & 0.50 & 0.29 & 0.48 & 0.50 \\ 1 & 1 & 0.37 & 0.51 & 1 & 1 & 0.51 & 0.51 & 0.41 & 0.55 & 0.52 & 1 & 0.49 & - & 0.29 & 0.48 & 0.51 \\ 0.50 & 1 & 1 & 1 & 1 & 0.50 & 1 & 0.50 & 1 & 1 & 1 & 1 & 1 & 1 & - & 1 & 1 \\ 1 & 1 & 1 & 0.51 & 1 & 1 & 0.51 & 0.51 & 0.38 & 0.51 & 0.52 & 1 & 0.49 & 0.48 & 0.30 & - & 0.51 \\ 1 & 1 & 1 & 0.48 & 1 & 0.29 & 0.48 & 0.48 & 1 & 0.48 & 0.50 & 0.34 & 0.48 & 0.50 & 1 & 0.35 & -\end{array}\right\}$

\section{CONCLUSION}

The IF ELECTRE method is provided for solving multicriterial problem with IFS information. The IFS data are used instead of single values in the evaluation process of the ELECTRE method. With these data, different sets of concordance and discordance are classified to fit a real life decision. IF ELECTRE algorithm is proposed to support final decision makers in managing the project of removal of construction barriers in HSs. There were 17 HSs defined for evaluation by seven criteria. Three DMs are included in the process according to their background and the years of experience to lower a partiality in the decision-making process. Hereby, proposed model uses determined concordance and discordance sets to construct concordance and discordance matrices. Defining these matrices, an aggregated matrix is calculated and the final ranking of HSs is achieved. Technic school is rank with the highest priority for the removal of construction barriers, and the least necessary is the Trade-technic school. These school are ranked according to the number and complexity of barriers that need to be remove. Only the crucial criteria are included in the assessment process, to lower the comprehensives of the calculations and results. Since the problem is multicirterial with large amount of uncertain data, therefore the proposed IF ELECTRE is an effective approach because fuzzy theory can precisely resolve the natural duality associated with the DM's definition of uncertain data. Furthermore, the approach enables DMs to select the best alternative by determine the shortest distance form positive ideal solution and negative ideal solution. The IF ELECTRE hereby, is used to define the HS that is the most necessary for the construction barriers removal and then by the final ranking of all HSs, defined the plan for the removal projects. For distance measure calculation of discordance index, the Euclidian distance is used. This approach gives more systematic description of the decision process, and it removes the ambiguity and vagueness in collected data. It has the ability to solve other complex problems with the high degree of uncertainty and hesitation. For the future study, more criteria described by interval valued IF information will be defined to achieve a detailed evaluation of alternatives, integrating users' opinions.

\section{Acknowledgment}

This research is partially supported through project KK.01.1.1.02.0027, a project co-financed by the Croatian Government and the European Union through the European Regional Development Fund - the Competitiveness and Cohesion Operational Programme.

\section{Notice}

This paper was presented at IC2ST-2021 - International Conference on Convergence of Smart Technologies. This conference was organized in Pune, India by Aspire Research Foundation, January 9-10, 2021. The paper will not be published anywhere else.

\section{REFERENCES}

[1] Gray, D. B., Gould, M., \& Bickenbach, J. E. (2003). Environmental barriers and disabilities. Journal of Architectural and Planning Research, 20(1), 30-37.

[2] Kassab, M., Hegazy, T., \& Hipel, K. (2010). Computerized DSS for construction conflict resolution under uncertainty. $J$. Constr. Eng. Manage. 136(12), 1249-1257. https://doi.org/0.1061/(ASCE)CO.1943-7862.0000239

[3] Zadeh, L. A. (1965). Fuzzy sets. Information and Control, 8(3), 338-353. https://doi.org/10.1016/S0019-9958(65)90241-X

[4] Atanassov, K. T. (1986). Intuitionistic fuzzy sets. Fuzzy sets and Systems, 20(1), 87-96. https://doi.org/10.1016/S0165-0114(86)80034-3

[5] Atanassov, K. T. (1999). Intuitionistic fuzzy sets: Theory and applications. New York: Physica-Verlag. https://doi.org/10.1007/978-3-7908-1870-3

[6] Atanassov, K., Pasi, G., \& Yager, R. (2005). Intuitionistic fuzzy interpretations of multi-criteria multi-person and multimeasurement tool decision making. International Journal of Systems Science, 36(14), 859-868. https://doi.org/10.1080/00207720500382365

[7] Hong, D. H. \& Choi, C. H. (2000). Multicriteria fuzzy decisionmaking problems based on vague set theory. Fuzzy Sets and Systems, 114(1), 103-113. https://doi.org/10.1016/S0165-0114(98)00271-1 
[8] Hung, W. L. \& Yang, M. S. (2004). Similarity measures of intuitionistic fuzzy sets based on Hausdorff distance. Pattern Recognition Letters, 25, 1603-1611. https://doi.org/10.1016/j.patrec.2004.06.006

[9] Liu, H. W. \& Wang, G. J. (2007). Multi-criteria decisionmaking methods based on intuitionistic fuzzy sets. European Journal of Operational Research, 179(1), 220-233. https://doi.org/10.1016/j.ejor.2006.04.009

[10] Szmidt, E. \& Kacprzyk, J. (2002). Using intuitionistic fuzzy sets in group decision making. Control and Cybernetics, 31, $1037-1053$

[11] Szmidt, E. \& Kacprzyk, J. (2003). A consensus-reaching process under intuitionistic fuzzy preference relations. International Journal of Intelligent Systems, 18, 837-852. https://doi.org/10.1002/int.10119

[12] Wang, P. (2009). QoS-aware web services selection with intuitionistic fuzzy set under consumer's vague perception. Expert Systems with Applications, 36(3), 4460-4466. https://doi.org/10.1016/j.eswa.2008.05.007

[13] Xu, Z. S. (2007a). A survey of preference relations. International Journal of General Systems, 36(2), 179-203. https://doi.org/10.1080/03081070600913726

[14] Xu, Z. S. (2007b). Some similarity measures of intuitionistic fuzzy sets and their applications to multiple attribute decision making. Fuzzy Optimization and Decision Making, 6(2), 109121. https://doi.org/10.1007/s10700-007-9004-z

[15] Xu, Z. S. (2007c). Intuitionistic fuzzy aggregation operators. IEEE Transactions on Fuzzy Systems, 15(6), 1179-1187. https://doi.org/10.1109/TFUZZ.2006.890678

[16] Xu, Z. \& Yager, R. R. (2009). Intuitionistic and interval-valued intuitionistic fuzzy preference relations and their measures of similarity for the evaluation of agreement within a group. Fuzzy Optimization and Decision Making, 8(4), 123-139. https://doi.org/10.1007/s10700-009-9056-3

[17] Li, D. F. \& Cheng, C. T. (2002). New similarity measures of intuitionistic fuzzy sets and application to pattern recognitions. Pattern Recognition Letters, 23, 221-225. https://doi.org/10.1016/S0167-8655(01)00110-6

[18] Liang, Z. \& Shi, P. (2003). Similarity measures on intuitionistic fuzzy sets. Pattern Recognition Letters, 24, 2687-2693. https://doi.org/10.1016/S0167-8655(03)00111-9

[19] Vlachos, I. K. \& Sergiadis, G. D. (2007). Intuitionistic fuzzy information? Applications to pattern recognition. Pattern Recognition Letters, 28, 197-206. https://doi.org/10.1016/j.patrec.2006.07.004

[20] Wang, W. \& Xin, X. (2005). Distance measure between intuitionistic fuzzy sets. Pattern Recognition Letters, 26, 20632069. https://doi.org/10.1016/j.patrec.2005.03.018

[21] Zhang, C. \& Fu, H. (2006). Similarity measures on three kinds of fuzzy sets. Pattern Recognition Letters, 27, 1307-1317. https://doi.org/10.1016/j.patrec.2005.11.020

[22] Boran, F. E. (2011). An integrated intuitionistic fuzzy multi criteria decision making method for facility location selection. Mathematical and Computational Applications, 16, 487-496. https://doi.org/10.3390/mca16020487

[23] Rouyendegh, B. D. (2018). The Intuitionistic Fuzzy ELECTRE model. International Journal of Management Science and Engineering Management, 13(2), 139-145. https://doi.org/10.1080/17509653.2017.1349625

[24] Boran, F. E., Genc, S., Kurt, M., \& Akay, D. (2009). A multicriteria intuitionistic fuzzy group decision making for selection of supplier with TOPSIS method. Expert Systems with Applications, 36(8), 11363-11368. https://doi.org/10.1016/j.eswa.2009.03.039
[25] Boran, F. E., Boran, K., \& Menlik, T. (2012). The evaluation of renewable energy technologies for electricity generation in Turkey using intuitionistic fuzzy TOPSIS. Energy Sources Part B, 7, 81-90. https://doi.org/10.1080/15567240903047483

[26] Roy, B. (1968). Classement et a choix en presence de points de vue multiples (la methode Electre) [Ranking and choice in the presence of multiple points of view]. RIRO, 8, 57-75. https://doi.org/10.1051/ro/196802V100571

[27] Benayoun, R. \& Billsberry, J. (2007). Experiencing recruitment and selection. Hoboken, NJ, Wiley \&Sons.

[28] Hashemi, S. S., Hajiagha, S. H. R., Zavadskas, E. K., \& Mahdiraji, H. A. (2016). Multicriteria group decision making with ELECTRE III method based on interval-valued intuitionistic fuzzy information. Applied Mathematical Modelling, 40, 1554-1564. https://doi.org/10.1016/j.apm.2015.08.011

[29] Roy, B. (1978). ELECTRE III: Un algorithme de classements fonde sur une representation floue des preferenceen presence de criteres multiples [An algorithm of rankings based on a fuzzy representation of the preference in the presence of multiple criteria]. Cahiers de CERO, 20, 3-24.

[30] Beccali, M., Cellura, M., \& Ardente, D. (1998). Decision making in energy planning: The ELECTRE multicriteria analysis approach compared to a fuzzy-sets methodology. Energy Conversion and Management, 39(16-18), 1869-1881. https://doi.org/10.1016/S0196-8904(98)00053-3

[31] Chen, T. Y. (2016). An IVIF-ELECTRE outranking method for multiple criteria decision-making with interval-valued intuitionistic fuzzy sets. Technological and Economic Development of Economy, 22, 416-452. https://doi.org/10.3846/20294913.2015.1072751

[32] Wu, M. C. \& Chen, T. Y. (2011). The ELECTRE multicriteria analysis approach based on Atanassov's intuitionistic fuzzy sets. Expert Systems with Applications, 38, 12318-12327. https://doi.org/10.1016/j.eswa.2011.04.010

[33] Rouyendegh, B. D. \& Erol, S. (2012). Selecting the best project using the Fuzzy ELECTRE method. Mathematical Problem in Engineering, 2012, 1-12. https://doi.org/10.1155/2012/790142

[34] Woolley, H. (2013). Now being social: The barrier of designing outdoor play spaces for disabled children. Children Soc., 27, 448-458. https://doi.org/10.1111/j.1099-0860.2012.00464.x

[35] Agarwal, N., Moya, E. M., Yasui, N. Y., \& Seymour, C. (2015). Participatory action research with college students with disabilities: Photovoice for an inclusive campus. $J$. Postsecondary Educ. Disability, 28(2), 243-250.

[36] Hammel, J. et al. (2015). Environmental barriers and supports to everyday participation: A qualitative insider perspective from people with disabilities. Arch. Phys. Med. Rehabil., 96(4), 578-588. https://doi.org/10.1016/j.apmr.2014.12.008

[37] Church, L. R. \& Marston, J. R. (2003). Measuring accessibility for people with a disability. Geog. Anal., 35(1), 83-96. https://doi.org/10.1111/j.1538-4632.2003.tb01102.x

[38] Martin, J. J. (2013). Benefits and barriers to physical activity for individuals with disabilities: A social-relational model of disability perspective. Disability Rehabil., 35(24), 2030-2037. https://doi.org/10.3109/09638288.2013.802377

[39] Hannon, B. (2014). Exploring the accessibility of leisure facilities in Munster for people with physical disabilities. CARL research project, Univ. College Cork, Cork, Ireland.

[40] Kroll, T., Jones, G. C., Keh, M., \& Neri, M. T. (2006). Barriers and strategies affecting the utilisation of primary preventive services for people with physical disabilities: A qualitative inquiry. Health Soc. Care Commun., 14(4), 284-293. https://doi.org/10.1111/j.1365-2524.2006.00613.x 
[41] Kayes, N. M., McPherson, K. M., Taylor, D., Schlüter, P. J., \& Kolt, G. S. (2011). Facilitators and barriers to engagement in physical activity for people with multiple sclerosis: A qualitative investigation. Disability Rehabil., 33(8), 625-642. https://doi.org/10.3109/09638288.2010.505992

[42] Yuker, H. E., Revenson, J., \& Fracchia, J. F. (1968). The modification of educational equipment and curriculum for maximum utilization by physically disabled persons, Human Resources Center, Albertson, NY.

[43] Leigh Hill, J. (1992). Accessibility: Students with disabilities in universities in Canada. Can. J. Higher Educ., 22(1), 48-83.

[44] Klinger, L. E. (2014). Scoping review-Physical accessibility and postsecondary education. Occupational Therapy Publications, Paper 7. hhttp://ir.lib.uwo.ca/otpub/7i (Nov. 17, 2016).

[45] Burton, G., Sayrafi, I., \& Srour, S. A. (2013). Inclusion or transformation? An early assessment of an empowerment project for disabled people in occupied Palestine. Disability Soc., 28(6), 812-825. https://doi.org/10.1080/09687599.2013.802223

[46] Ginis, K. A. M., Ma, J. K., Latimer-Cheung, A. E., \& Rimmer, J. H. (2016). A systematic review of review articles addressing factors related to physical activity participation among children and adults with physical disabilities. Health Psychol. Rev., 10(4), 478-494. https://doi.org/10.1080/17437199.2016.1198240

[47] Saaty, T. L. (1996). Decision making with dependence and feedback, the analytic network process. Pittsburgh, PA: RWS Publications.

[48] Boran, F. E., Genc, S., Kurt, M., \& Akay, D. (2009). A multicriteria intuitionistic fuzzy group decision making for supplier selection with TOPSIS method. Expert Systems with Applications, 36, 11363-11368. https://doi.org/10.1016/j.eswa.2009.03.039

[49] Szmidt, E., \& Kacprzyk, J. (2000). Distances between intuitionistic fuzzy sets. Fuzzy Sets and Systems, 114(3), 505518. https://doi.org/10.1016/S0165-0114(98)00244-9

[50] Rogulj, K. \& Jajac, N. (2018). Achieving a construction barriers free-environment: Decision Support to Policy Selection. Journal of Management in Engineering (ASCE). 04018020-1-18.

https://doi.org/10.1061/(ASCE)ME.1943-5479.0000618

\section{Authors' contacts:}

Katarina Rogulj, Assist. Prof.

University of Split,

Faculty of Civil Engineering, Architecture and Geodesy,

Matice hrvatske 15, 21000 Split, Croatia

e-mail: katarina.rogulj@gradst.hr

Jelena Kilić Pamuković, Assist. Prof. University of Split,

Faculty of Civil Engineering, Architecture and Geodesy,

Matice hrvatske 15, 21000 Split, Croatia

e-mail: jelena.kilicj@gradst.hr 